\title{
Jonathan Pérez Mostazo, Lustrando las raíces. Antigüedad vasca, política e identidades en el siglo XIX. Pamplona: Urgoiti Editores, 2019, 496 págs.
}

Es muy adecuado comenzar este comentario con una célebre anécdota, la protagonizada por el rector de la Universidad de Cervera cuando, dirigiéndose al rey Fernando VII para celebrar la reapertura de las universidades, afirmó enfáticamente: "lejos de nosotros la funesta manía de pensar". No quería decir con ello que los miembros de su claustro fuesen unos ineptos, sino que no compartían en absoluto los ideales de la Ilustración, que con su culto a la diosa Razón habría desembocado en la Revolución francesa, y que por supuesto avalaban el retorno del absolutismo.

En esta anécdota podemos observar una doble maldición, que se explica muy bien a lo largo de las páginas del libro. Por un parte la del mediocre destino de las humanidades hispánicas, que ya Luis Gil explicó en su estudio sobre el humanismo español como un doble fracaso, debido a una fallida introducción de la imprenta, que junto con la Contrarreforma tridentina abortó el desarrollo del humanismo, clave para el futuro desarrollo de los estudios clásicos; y por otra parte la de una especie de odio visceral que muchos historiadores han tenido al pensamiento, lo que ha dificultado el desarrollo de nuestros estudios historiográficos hasta hace relativamente poco tiempo. Unos estudios de los que el libro de Jonathan Pérez Mostazo es una excelente muestra de maestría y rigor académicos.

Parte nuestro autor del maestro de todos los estudiosos de la historiografía de la Antiguiedad, Arnaldo Momigliano, y retornando a él sería conveniente insistir en la diferencia entre lo que él mismo denominó el historiador y el anticuario, muy útil para nosotros a la hora de enfrenarnos con la erudición, a veces minuciosa en exceso, de numerosos aficionados que en País Vasco, Galicia o Cataluña, y también en el resto de España, dedicaron lo mejor de sus saberes, sus esfuerzos, y a veces de sus propios caudales, para tratar de comprender la realidad geográfica e histórica de las tierras en las que habían nacido y en las que vivían, y que normalmente eran dejadas a un lado por los escritores de las grandes Historias de España.

Friedrich Nietzsche había establecido una distinción entre tres clases de historiadores: el anticuario, que suele ser un erudito local ingenuo y muchas veces inocuo; el monumental, que escribe las grandes historias patrias que ponen en acción el amor y el odio necesarios para llevar a los ciudadanos a la guerra; y el historiador crítico, que intenta que la historia sea una herramienta útil para la vida. A lo largo del estudio de Pérez Mostazo podemos observar cómo no ha habido en el siglo XIX historiadores críticos, sino únicamente anticuarios que aspiraron a convertirse en historiadores monumentales, utilizando a la historia como instrumento de la movilización política, tanto en el País Vasco como en España, en la que ese papel crítico para la historia sería reivindicado en el siglo XX como labor más propia de la filosofía, ya sea con la intrahistoria de Miguel de Unamuno, o la historiología de Ortega y Gasset. En la actualidad esa misión de la historia como instrumento de crítica social y política se le suele atribuir al estudio de la historiografía, pues su misión consiste en estudiar cómo es posible el conocimiento histórico, cuál es su valor y cuáles son sus límites. Esta es la labor a la que ha dedicado sus esfuerzos, centrándose en el siglo XIX y el País Vasco, nuestro autor.

El argumento básico de la obra es el proceso en el que, por decirlo de alguna forma, se fue gestando la transición entre los cántabros y los vascos como pueblos 
protagonistas de la historia nacional de un futuro país. Todas las historias nacionales tienen la misma estructura. Todas ellas tienen la forma de una narración en la que se desarrolla una acción, que normalmente es de carácter bélico y diplomático, sobre un territorio o escenario, que es el solar patrio, y que se define como un territorio dotado de un extraordinario valor simbólico. No en vano atravesar sus fronteras por la fuerza se denomina violación Y no en vano la tierra patria es llamada madre.

En ese territorio un protagonista, o sujeto político a la vez que narrativo, intenta conseguir un fin, que suele ser la independencia o liberación de él mismo, del pueblo. Para lograrlo dispondrá de medios materiales y de aliados y se enfrentará a uno o varios antagonistas, que pueden residir en el interior de su propio territorio, o más allá de sus fronteras. Podemos ver en el libro como todos estos elementos están presentes en los historiadores y anticuarios del siglo XIX, cuya obra, enraizada en la tradición anterior, configura lo que serán el nacionalismo y la historiografía vascos hasta el momento presente. Lo que ocurre es que en este caso se darán una serie de dificultades añadidas a las que comparten todas las historiografías periféricas en España.

En el caso de Galicia, Cataluña, y ya no digamos Navarra, todas estas historiografías pueden tomar como referente previo algún reino, aunque a veces sea un poco más literal que real, como lo fue el reino de Galicia, o el condado de Barcelona y la marca hispánica, como precedentes de una Cataluña en relación constante con el reino de Aragón. En el caso de Navarra ese reino tuvo una existencia indudable en las edades Media y Moderna, por lo que la historiografía de Navarra posee una entidad propia. Sin embargo, su propia historia se va a ver entremezclada con la que quisieron escribir nuestros autores vascos, que al carecer de un precedente histórico claro para el País Vasco, tuvieron que oscilar entre dos polos: cántabros y vascones, vascos y navarros, cuando no vascos y castellanos.

Esa indefinición política también lo fue geográfica, ya que el territorio de un reino que no tuvo existencia, como no se podía inventar, es sustituido por otros tipos de territorios basados en la lengua, la raza o las tradiciones populares. Unos territorios que incluirán a veces a una parte o toda Navarra, o una parte de la actual Francia, definida ahora como Iparralde, y a partes de la Rioja, o incluso Castilla. El gran interés del estudio de Pérez Mostazo es la minuciosa descripción de todas estas tensiones en las obras de unos autores en los que quizás debía había haber destacado un poco más que a veces eran aficionados de buena voluntad, a los que no cabe exigir el rigor metodológico y el cumplimiento de los patrones propios de los historiadores académicos, que nunca en el siglo XIX quisieron estudiar con detenimiento la realidad histórica de este pueblo.

La primera tensión dialéctica está entre los cántabros y los vascones. Se toma a los cántabros como referente porque son conocidos en las fuentes clásicas por su heroica lucha contra Roma. Una lucha que será tomada como modelo narrativo plurisecular de la resistencia frente al extranjero y frente al invasor. Lo que ocurre es que Cantabria está ahí, en los lindes de las antiguas provincias vascas, siempre identificadas con Castilla por sus habitantes y sus cronistas, y por eso decae el modelo cántabro para dejar paso a la construcción progresiva del pueblo vasco como sujeto narrativo.

El siguiente péndulo dialéctico es el centrado en torno a los fueros y las reivindicaciones foralistas, de cuya existencia no se puede dudar. Lo que ocurre es que la lucha por los fueros fue protagonizada en gran parte por Navarra, y por eso llegó un 
momento en el que fue necesario ir rompiendo lazos con el fuerismo, y su posterior vinculación al catolicismo y el tradicionalismo, unidos a su lucha contra la modernidad y el laicismo, todas ellas encarnadas en el carlismo, para conseguir crear el sujeto narrativo y político específico del pueblo vasco.

Para lograrlo los mejores referentes o índices serían el euskera, también compartido con Navarra y los territorios definidos como Euskal Herria, o tierra de los que hablan el vascuence, en España y Francia, y posteriormente la raza, diferenciable por los ocho apellidos vascos, que no son más que los ocho apellidos de los estatutos de limpieza de sangre inquisitoriales que permitían distinguir a los enemigos ocultos: los criptojudios.

La lengua y la raza tenían la ventaja de su singularidad, real en el caso de la lengua, o imaginaria, en el caso de los caracteres raciales, que como eran imposibles de definir somáticamente, se definieron mediante unos apellidos exclusivos de la lengua vasca. Y esa singularidad permitió definirlas como algo único, antiquísimo, y por lo tanto lo más auténtico, lo más primigenio, y que como tal garantizaría el derecho radical a la diferencia y a la independencia. Si a ambos unimos el estudio del folklore en todas sus facetas podremos ver cómo se cierra sobre sí mismo un círculo perfecto.

Ese círculo perfecto es el del nacionalismo vasco en sus caracteres esenciales, y la base de su historiografía nacionalista. La genealogía de ese círculo es lo que nos narra Pérez Mostazo en este libro, centrándose prioritariamente en la historiografía relativa a las etapas prerromana y a la conquista romana. Su viaje ha sido contado con la paciencia de un archivero y la veracidad de un testigo fidedigno. En él se puede ver la pasión por el conocimiento y por el arte o la ciencia de la historia bien hecha, pero nunca el partidismo ni la pasión política. Nuestro autor ha cumplido el lema con el que Baruch Spinoza acaba su Etica: "ni reír ni llorar, sino comprender". Es de esa comprensión, que a veces solo la historia nos puede dar, de la que están necesitadas las universidades y la sociedad española del momento. Esperemos que este libro, que será referencia por muchos años, sirva como un modesto sillar en la construcción de nuestra convivencia.

José Carlos Bermejo Barrera

Universidad de Santiago de Compostela

josecarlos.bermejo@usc.es

Fecha de recepción: 20 de marzo de 2020

Fecha de aceptación: 18 de mayo de 2020

Publicación: 1 de julio de 2020

Para citar este artículo: José Carlos Bermejo Barrera, "Jonathan Pérez Mostazo, Lustrando las raíces. Antigüedad vasca, política e identidades en el siglo XIX. Pamplona: Urgoiti Editores, 2019, 496 págs.”, Historiografías, 19 (enero-junio, 2020), pp. 173-175. 